Artículo

\title{
Embriogénesis y organogénesis de aguacate criollo mexicano
}

\author{
Anareli Quintero-Jiménez ${ }^{1}$ \\ Elena Heredia-García ${ }^{2}$ \\ César L. Aguirre-Mancilla ${ }^{1}$ \\ Juan Carlos Raya-Pérez ${ }^{1}$ \\ Juan Gabriel Ramírez-Pimentel ${ }^{1}$ \\ Gabriel Iturriaga ${ }^{1 \S}$
}

${ }^{1}$ Tecnológico Nacional de México-Instituto Tecnológico de Roque (TecNM-IT Roque). Carretera CelayaJuventino Rosas km 8, Celaya, Guanajuato, México. CP. 38110. (anareli@yahoo.com; ceaguirre@itroque.edu.mx; juraya@itroque.edu.mx). ${ }^{2}$ Campo Experimental Bajío-INIFAP. Carretera Celaya-San Miguel de Allende km 6.5, Celaya, Guanajuato, México. CP. 38110. (elena_ herediag@yahoo.com.mx).

${ }^{\S}$ Autor para correspondencia: gaiturriaga@itroque.edu.mx.

\section{Resumen}

La variedad Drymifolia de aguacate (Persea americana Mill.) es usada generalmente como portainjerto por lo que es importante implementar las técnicas de embriogénesis somática y la organogénesis in vitro para su mejora genética, conservación y propagación clonal. En este trabajo se evaluaron embriogénesis somática directa, indirecta y organogénesis de la variedad Drymifolia. La germinación de los embriones somáticos maduros se indujo con $0.5 \mathrm{mg} \mathrm{L}^{-1}$ de 6-N-bencil amino purina (BAP) y $1 \mathrm{mg} \mathrm{L}^{-1}$ de ácido giberélico $\left(\mathrm{GA}_{3}\right)$. De las seis accesiones evaluadas, Celaya 79, Comonfort 53, San Miguel, BG24, BG181 y Zutano, solo San Miguel respondió al proceso de embriogénesis. En la embriogénesis directa la eficiencia más alta de regeneración se obtuvo con $0.2 \mathrm{mg} \mathrm{L}^{-1}$ de picloram (46\%) y $10 \mathrm{mg} \mathrm{L}^{-1}$ de ANA (40\%). En la embriogénesis indirecta la accesión San Miguel formó callos con $0.2 \mathrm{mg} \mathrm{L}^{-1}$ de picloram y tuvo una eficiencia de regeneración de $45 \%$ conservando su potencial de regeneración hasta por seis meses. Con respecto a la organogénesis, se cultivaron embriones cigóticos inmaduros decapitados en medio con reguladores de crecimiento o sin ellos y las seis accesiones respondieron positivamente a ambas condiciones. La accesión Comonfort 53 tuvo mayor eficiencia de regeneración (54\%) con reguladores de crecimiento. Este estudio realizado del 2016 a 2018, proporciona un enfoque nuevo y prometedor para la regeneración y multiplicación de plantas de P. americana var. Drymifolia a través de embriones cigóticos.

Palabras clave: aguacate, Drymifolia, micropropagación, regeneración in vitro.

Recibido: agosto de 2020

Aceptado: octubre de 2020 


\section{Introducción}

El aguacate (Persea americana Mill.) es uno de los frutos más importantes del mundo; ha sido reconocido por sus beneficios a la salud y descrito como el más nutritivo de todos los frutos, especialmente por los beneficios de sus ácidos grasos, por lo que se ha convertido en una parte importante de la dieta en muchos países (Fonseca et al., 2016). Según la FAO, México es el mayor productor de aguacate, que corresponde a $25 \%$ de la producción mundial (FAOSTAT, 2018).

Los principales factores que limitan la producción de aguacate son las plagas, las enfermedades (Ploetz et al., 2015; Sharma et al., 2017) y los factores abióticos (Bonomelli et al., 2018). El incorporar nuevas características en el aguacate mediante el mejoramiento genético es complicado, ya que tiene un período vegetativo largo de aproximadamente 6 a 8 años y las autopolinizaciones son difíciles debido a la protoginia (Imbert, 1997; Gazit y Degani, 2002). Por lo tanto, la producción comercial de aguacate se basa en injertar variedades que confieren tolerancia a patógenos y al estrés por frío (Whiley et al., 1990), tolerancia a la salinidad (Álvarez-Acosta et al., 2018) o tolerancia a la pudrición de la raíz (Van den Berg et al., 2018).

Algunos de estos portainjertos son híbridos de razas guatemaltecas o mexicanas; por ejemplo, $P$. americana var. Drymifolia es una raza mexicana que se usa frecuentemente como portainjerto en los huertos en nuestro país (Rincón-Hernández et al., 2011). Por lo que es de gran importancia implementar su propagación clonal, conservación de germoplasma y mejoramiento genético.

Para la conservación o mejoramiento genético in vitro se requiere tener un sistema de regeneración de una planta completa a través de la embriogénesis somática o la organogénesis adventicia. En la organogénesis los brotes pueden formarse directamente del explante o indirectamente a partir de callos. En contraste, la embriogénesis somática es un proceso que implica la formación de embriones a partir de células somáticas vegetales y, comparado con la organogénesis, es un proceso más lento e implica un riesgo de variación somaclonal (Fehér, 2019).

La eficiencia de regeneración de plantas de aguacate por organogénesis in vitro a partir de tejidos asexuales de árboles es baja y dependiente de la variedad (Bandaralage et al., 2017). Algunos reportes de micropropagación tuvieron éxito utilizando explantes nodales, tejidos juveniles y brotes axilares de plántulas de aguacate (Martínez-Pacheco et al., 2010). Sin embargo, los obstáculos para el establecimiento in vitro de aguacate han sido la contaminación por bacterias, hongos y el oscurecimiento del explante (Nhut et al., 2008).

La regeneración del aguacate por embriogénesis somática se ha descrito en diferentes variedades como Hass (Pliego-Alfaro y Murashige, 1988); Duke (Mooney y Van Staden, 1987), T372 (Witjaksono et al., 1998), Anaheim (Perán-Quesada et al., 2004), Duke 7 (Márquez-Martín et al., 2012) y Reed (Encina et al., 2014).

Para estudiar la vía de regeneración embriogénica del aguacate se han utilizado diferentes explantes, como embriones zigóticos inmaduros en estadio globular o nucela (Pliego-Alfaro y Murashige, 1988; Witjaksono y Litz, 1999; Suarez et al., 2006), pero aún no se ha reportado un sistema de embriogénesis para la variedad Drymifolia. En este trabajo presentamos un método eficiente para la regeneración de aguacate de esta variedad por la vía de organogénesis y embriogénesis somática a partir de embriones cigóticos inmaduros. 


\section{Materiales y métodos}

\section{Material vegetal}

El material vegetal se obtuvo del banco de germoplasma del Instituto Nacional de Investigaciones Forestales Agrícolas y Pecuarias en Celaya, México durante el ciclo primavera-verano. Los árboles de aguacate variedad Drymifolia tenían en promedio seis años y estos fueron fertilizados anualmente con NPK, (200-200-300) y Ca, Mg, Fe y Zn (25- 05-01-1.5). Se colectaron frutos inmaduros de aguacate de 5-8 cm de diámetro de las accesiones, Celaya 79, Comonfort 53, San Miguel, BG24, BG181 y Zutano (raza mexicana $\times$ raza guatemalteca) se lavaron con jabón desinfectante (Dermocleen ${ }^{\circledR}$ ) y se enjuagaron con agua de la llave; se embebieron en hipoclorito de sodio comercial (Clorale ${ }^{\circledR}$ ) durante 10 min y se enjuagaron tres veces durante un minuto en agua esterilizada. Como explante se usaron embriones cigóticos (EC) en etapa cotiledonar.

\section{Inducción de la embriogénesis directa en embriones somáticos}

El medio de inducción (I) consistió de las sales de Gamborg modificadas (GM) (Gamborg et al., 1968; Perán-Quesada et al., 2004) adicionadas con $1 \mathrm{mg} \mathrm{L}^{-1}$ de piridoxina, $1 \mathrm{mg} \mathrm{L}^{-1}$ de tiamina, $100 \mathrm{mg} \mathrm{L}^{-1}$ de mio-inositol, $1 \mathrm{~g} \mathrm{~L}^{-1}$ de carbón activado, $30 \mathrm{~g} \mathrm{~L}^{-1}$ de sacarosa, $8 \mathrm{~g} \mathrm{~L}^{-1}$ de agar (SigmaAldrich), y diferentes concentraciones de ácido 1-naftalenacético (ANA) (2, 5 o $\left.10 \mathrm{mg} \mathrm{L}^{-1}\right)$, ácido 2,4-diclorofenoxiacético (2,4-D) (5 o $10 \mathrm{mg} \mathrm{L}^{-1}$ ) o ácido 4-amino-3,5,6-tricloropicolínico (picloram) $\left(0.05,0.1 \circ 0.2 \mathrm{mg} \mathrm{L}^{-1}\right)$. El pH del medio se ajustó a 5.7, se esterilizaron en autoclave a $121{ }^{\circ} \mathrm{C}$ por $15 \mathrm{~min}$ y se vertieron $30 \mathrm{ml}$ por caja Petri $100 \times 25 \mathrm{~mm}$ ) en condiciones de campana de flujo laminar. Los EC de todas las accesiones se cultivaron en el medio I y se mantuvieron en oscuridad a $30{ }^{\circ} \mathrm{C}$ hasta la inducción de embriones somáticos (ES).

\section{Embriogénesis indirecta}

El medio de inducción de callos (IC) consistió en sales GM adicionado con $1 \mathrm{mg} \mathrm{L}^{-1}$ de piridoxina, $1 \mathrm{mg} \mathrm{L}^{-1}$ de tiamina, $100 \mathrm{mg} \mathrm{L}^{-1}$ de mio-inositol, $1 \mathrm{~g} \mathrm{~L}^{-1}$ de carbón activado, $30 \mathrm{~g} \mathrm{~L}^{-1}$ de sacarosa, $8 \mathrm{mg} \mathrm{L}^{-1}$ de agar (Sigma-Aldrich), $0.2 \mathrm{mg} \mathrm{L}^{-1}$ de picloram y se ajustó a pH 5.7. Los EC se cultivaron en IC y se mantuvieron en condiciones de oscuridad a $30{ }^{\circ} \mathrm{C}$ para la inducción de callo embriogénico (CE).

\section{Mantenimiento de callos embriogénicos}

Los callos embriogénicos (CE) se subcultivaron en IC cada dos semanas. En cada caja de Petri (100 x $15 \mathrm{~mm}$ ) que contenía $30 \mathrm{~mL}$ de IC con $0.2 \mathrm{mg} \mathrm{L}^{-1}$ de picloram, se cultivaron $50 \mathrm{mg}$ de CE y se mantuvieron a $30^{\circ} \mathrm{C}$ en la oscuridad. Se subcultivaron $50 \mathrm{mg}$ de $\mathrm{CE}$ viables por caja Petri semanalmente a lo largo de nueve meses.

\section{Maduración de embriones somáticos}

Para inducir la formación la maduración de ES estos se transfirieron a medio de maduración (M) que contenía sales GM adicionadas con $1 \mathrm{mg} \mathrm{L}^{-1}$ de piridoxina, $1 \mathrm{mg} \mathrm{L}^{-1}$ de tiamina, $100 \mathrm{mg} \mathrm{L}^{-1}$ de mio-inositol, $1 \mathrm{~g} \mathrm{~L}^{-1}$ de carbón activado, $30 \mathrm{~g} \mathrm{~L}^{-1}$ de sacarosa, $16 \mathrm{~g} \mathrm{~L}^{-1}$ de agar (Sigma-Aldrich) y 
$0.2 \mathrm{mg} \mathrm{L}^{-1}$ ácido 4-amino-3,5,6-tricloropicolínico (picloram). El pH del medio se ajustó a 5.7, se esterilizaron en autoclave a $121{ }^{\circ} \mathrm{C}$ por $15 \mathrm{~min}$ y se vertieron $30 \mathrm{ml}$ por caja Petri $(100 \times 25 \mathrm{~mm})$ en condiciones de campana de flujo laminar y se mantuvieron en condiciones de oscuridad a $30{ }^{\circ} \mathrm{C}$.

\section{Germinación de embriones maduros}

El medio de germinación (GE) consistió de las sales GM (Gamborg et al., 1968) adicionadas con $1 \mathrm{mg} \mathrm{L}^{-1}$ de piridoxina, $1 \mathrm{mg} \mathrm{L}^{-1}$ de tiamina, $100 \mathrm{mg} \mathrm{L}^{-1}$ de mio-inositol, $50 \mathrm{~g} \mathrm{~L}^{-1}$ de sacarosa, 2.5 g L $^{-1}$ Phytagel $^{\circledR}$ (Sigma-Aldrich), $0.5 \mathrm{mg} \mathrm{L}^{-1}$ BAP, $1 \mathrm{mg} \mathrm{L}^{-1}$ de $\mathrm{AG}_{3}$; el pH del medio se ajustó a 5.7. ES maduros en etapa colitedonar con un diámetro de aproximadamente 5-10 $\mathrm{mm}$ se colocaron en cajas Petri (10 por caja). Los ES maduros se subcultivaron en un medio fresco cada dos semanas durante un período de seis a ocho semanas hasta la germinación. Los cultivos se incubaron en una cámara de crecimiento a $25 \pm 2{ }^{\circ} \mathrm{C}$ con $16 \mathrm{~h}$ de luz e intensidad lumínica de $30 \mu \mathrm{mol} \mathrm{m}^{-2} \mathrm{~s}^{-1}$ proporcionada por lámparas fluorescentes de luz blanca fría de $40 \mathrm{~W}$ (Osram, Monterrey, Nuevo León, México).

\section{Inducción de la organogénesis}

Los meristemos apicales se disectaron de los EC de las accesiones utilizadas y se cultivaron en el medio de inducción (I) de la organogénesis que consistió de las sales GM, $30 \mathrm{mg} \mathrm{L}^{-1}$ de sacarosa, $1 \mathrm{mg} \mathrm{L}^{-1}$ de piridoxina, $1 \mathrm{mg} \mathrm{L}^{-1}$ de tiamina, $100 \mathrm{mg} \mathrm{L}^{-1}$ de mio-inositol, $2.5 \mathrm{~g} \mathrm{~L}^{-1} \mathrm{de} \mathrm{Phytagel}^{\circledR}$ (Sigma-Aldrich), con reguladores de crecimiento (RC) $0.5 \mathrm{mg} \mathrm{L}^{-1}$ de BAP y $1 \mathrm{mg} \mathrm{L}^{-1} \mathrm{AG}_{3}$ o sin reguladores de crecimiento (SRC). El pH del medio se ajustó a 5.7 antes de su esterilización en autoclave $121{ }^{\circ} \mathrm{C}$ por $15 \mathrm{~min}$. En frascos de cristal de $120 \mathrm{ml}$ se vertieron $30 \mathrm{ml}$ de medio y se colocaron dos explantes en cada uno. Los cultivos se mantuvieron en una cámara de crecimiento a $25 \pm 2{ }^{\circ} \mathrm{C}$ con $16 \mathrm{~h}$ de luz.

\section{Crecimiento y enraizamiento de las plántulas y brotes adventicios}

El medio de enraizamiento $(\mathrm{R})$ estuvo compuesto por las sales $\mathrm{GM}$ adicionadas con $1 \mathrm{mg} \mathrm{L}^{-1}$ de piridoxina, $1 \mathrm{mg} \mathrm{L}^{-1}$ de tiamina, $100 \mathrm{mg} \mathrm{L}^{-1}$ de mio-inositol, $25 \mathrm{mg} \mathrm{L}^{-1}$ de ácido indol-3-butírico (AIB), $30 \mathrm{~g} \mathrm{~L}^{-1}$ de sacarosa $2.5 \mathrm{mg} \mathrm{L}^{-1}$ Phytagel $^{\circledR}$ (Sigma-Aldrich), el pH del medio se ajustó a 5.7. Se vertieron $30 \mathrm{ml}$ del en frascos de vidrio de $120 \mathrm{ml}$ y se colocó una plántula en cada uno. Los ES germinados y los brotes de $2 \mathrm{~cm}$ de longitud obtenidos por organogénesis se transfirieron a un medio de enraizamiento durante aproximadamente 4-5 semanas.

Posteriormente, las plántulas se colocaron en medio de elongación (E) en recipientes Magenta ${ }^{\circledR}$ con un medio de cultivo con la mitad de la concentración de las sales MS (Murashige y Skoog, 1962), adicionadas con $1 \mathrm{mg} \mathrm{L}^{-1}$ de piridoxina, $1 \mathrm{mg} \mathrm{L}^{-1}$ de tiamina, $100 \mathrm{mg} \mathrm{L}^{-1}$ de mio-inositol, $2.5 \mathrm{~g} \mathrm{~L}^{-1}$ Phytagel $^{\circledR}$ (Sigma-Aldrich), ajustando su pH a 5.7.

Las plántulas regeneradas in vitro se transfirieron a macetas con vermiculita (Termolita, Santa Catarina, Nuevo León, México) y se cubrieron con bolsas de plástico para favorecer su adaptación ex vitro. Se regaron con la mitad de la concentración del medio Murashige y Skoog (MS) cada 3 días y se cultivaron a $25 \pm 2{ }^{\circ} \mathrm{C}$ con 16 h de luz en una cámara de crecimiento como se describió anteriormente y se mantuvieron en estas condiciones durante dos meses aproximadamente. Posteriormente se retiró la bolsa de plástico y se aclimataron en condiciones en el invernadero (25$28{ }^{\circ} \mathrm{C}$ y $170-285 \mathrm{mmol} \mathrm{m}^{-2} \mathrm{~s}^{-1}$ de intensidad lumínica). 


\section{Análisis estadístico}

Para la embriogénesis somática directa e indirecta, la unidad experimental (UE) fue una caja de Petri con 5 EC, cada uno con tres repeticiones por cada accesión (Celaya 79, Comonfort 53, San Miguel, BG24, BG181 y Zutano) y diferentes concentraciones de ANA (2, 5 o $10 \mathrm{mg} \mathrm{L}^{-1}$ ), 2,4-D

(5 o $10 \mathrm{mg} \mathrm{L}^{-1}$ ) o picloram $\left(0.05,0.1\right.$ o $0.2 \mathrm{mg} \mathrm{L}^{-1}$ ). Para evaluar la viabilidad de los callos embriogénicos a través del tiempo se utilizaron $50 \mathrm{mg}$ de callos por caja Petri se usaron como UE con 5 repeticiones y se evaluó la regeneración al mes 1, 3, 6 y 9 de haber sido inducidos. La UE para la organogénesis fue una caja de Petri con 10 explantes de cada accesión y cinco réplicas con reguladores de crecimiento $\left(0.5 \mathrm{mg} \mathrm{L}^{-1}\right.$ de BAP y $\left.1 \mathrm{mg} \mathrm{L}^{-1} \mathrm{AG}_{3}\right)$ o sin ellos. Para cada experimento se utilizó un diseño completamente al azar. La significancia se determinó por análisis de varianza con SAS (SAS Institute Inc., 2012) y la prueba de Tukey $(p \leq 0.05)$ para la comparación de medias.

\section{Resultados y discusión}

\section{Embriogénesis directa}

En trabajos previos de regeneración in vitro de aguacate de Persea americana var. Hass, se utilizaron frutos inmaduros para extraer embriones cigóticos (EC) en la etapa globular (PliegoAlfaro y Murashige, 1988; Witjaksono y Litz, 1999). En contraste, en este trabajo se utlizaron frutos inmaduros diferentes accesiones de $P$. americana var. Drymifolia y del híbrido Zutano (Figura 1A) para aislar EC en etapa cotiledonar (Figura 1B). Todos los EC mostraron primordios foliares, hipocotilo y ápice radicular (Figura 1C). Solo los EC de la accesión San Miguel respondieron a los diferentes tratamientos de inducción de la embriogénesis somática directa. Esto coincide con otros autores (Pliego-Alfaro y Murashige, 1988; Witjaksono y Litz, 1999; Raharjo y Litz, 2005), quienes observaron que la respuesta embriogénica de los explantes depende del genotipo. Los EC formaron ES en etapa globular en la zona de la radícula 15 días después de su cultivo en el medio I (Figura 1D).

Fehér (2019) indicó que esto puede deberse a que el inicio de la formación de embriones puede ocurrir a partir de células del periciclo tipo células madre y que es posible que la embriogénesis comparta pasos iniciales con la formación de raíces laterales. Después de 15 días en medio I se identificó que los grupos de ES que se formaron por explante se desarrollaban sincronizadamente en algunos explantes (Figura 1E) y en otros EC las fases de desarrollo eran diferentes (globular, torpedo y corazón) (Figura $1 \mathrm{~F} \mathrm{y} \mathrm{G).} \mathrm{La} \mathrm{maduración} \mathrm{de} \mathrm{los} \mathrm{ES} \mathrm{ocurrió} \mathrm{en} \mathrm{el} \mathrm{medio} \mathrm{M} \mathrm{con} 0.2 \mathrm{mg}$ $\mathrm{L}^{-1}$ de picloram y un indicador fue el cambio de color, de translúcido (Figura 1F) a blanco opaco (Figura 1G), además de un cambio en el estado de desarrollo por su transición a etapa cotiledonar, la cual ocurrió aproximadamente dos semanas después de cultivo en el medio M (Figura 1H).

En esta etapa de maduración, los ES se escindieron del EC (Figura 1H) y se mantuvieron en el mismo medio hasta que alcanzaron un tamaño de 5-10 mm (dos semanas). Después de este tiempo, los ES se transfirieron al medio GE (Figura 1I), donde después de 15 días en presencia de luz, los embriones maduros comenzaron a fotosintetizar y germinaron después de 30 días de cultivo en el medio GE (Figura 1J). Este resultado contrasta con lo reportado por Encina et al. (2014), en donde se requirió del doble de tiempo para obtener resultados similares con las variedades de aguacate Duke, Hass, Anaheim y A10 por la vía de embriogénesis indirecta y con cultivos en suspensión. 


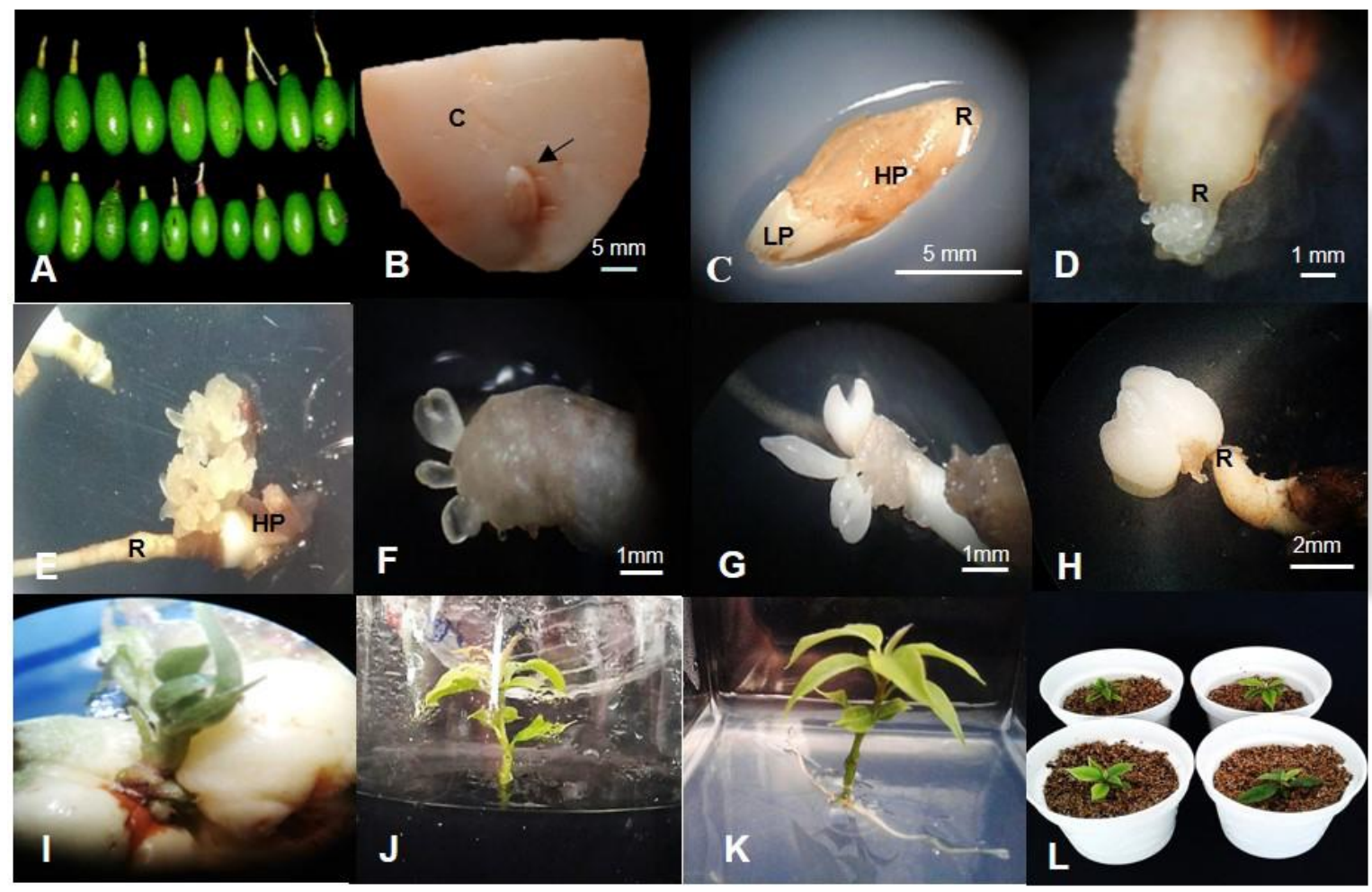

Figura 1. Embriogénesis somática directa en $P$. americana var. Drymifolia. A) frutos inmaduros de 5$8 \mathrm{~cm}$ de diámetro; B) embrión cigótico (EC) señalado por la flecha, cotiledón (C); C) EC, primordios foliares (LP), hipocotilo (HP), radícula (R); D) embriones somáticos (ES) en etapa globular en la radícula $(R)$ después de una semana en medio de inducción y maduración ( $0.2 \mathrm{mg} \mathrm{L}^{-1}$ picloram); E) ES después de dos semanas en medio de inducción y maduración; F) ES con aspecto translúcido en el EC; G) ES en maduración; H) ES maduro separado de la radícula; I) germinación de ES maduro; J) brotes en medio de enraizamiento; K) plántula en medio de elongación; y L) plantas aclimatadas en condiciones de invernadero (después de 3 meses).

Además, se observó que no todos los embriones maduros germinaron bipolarmente (ápice y raíz). Esto probablemente se debe a que la conversión de ES a planta con germinación bipolar se presenta en una frecuencia baja (Raharjo y Litz, 2003). Pliego-Alfaro y Murashige (1988) informaron que los meristemos no logran organizarse en la mayoría de los ES de aguacate, y que esto impide la germinación bipolar.

Por esta razón en el presente estudio, los embriones unipolares germinados con aproximadamente $2 \mathrm{~cm}$ de altura (3 semanas en GE aproximadamente) se separaron de los cotiledones y se transfirieron al medio R (Figura 1J). Posteriormente, se transfirieron al medio E para promover la elongación de la parte apical y el crecimiento del sistema radicular (Figura 1K). Finalmente, se necesitaron dos meses para adaptarlas a las condiciones ex vitro (Figura 1L). Los tratamientos que promovieron el porcentaje más alto de explantes que formaron embriones somáticos, contenían 10 mg L ${ }^{-1}$ ANA (66.6\%) o $0.2 \mathrm{mg} \mathrm{L}^{-1}$ picloram (46.6\%), estos mismos tratamientos indujeron el mayor número de embriones por explante (Cuadro 1). 
Cuadro 1. Embriogénesis somática de $P$. americana var. Drymifolia accesión San Miguel.

\begin{tabular}{cccccc}
\hline Auxinas & $\begin{array}{c}\text { Concentración } \\
\left(\mathrm{mg} \mathrm{L}^{-1}\right)\end{array}$ & $\begin{array}{c}\text { Explantes con } \\
\text { embriogénesis } \\
\text { somática }(\%)\end{array}$ & $\begin{array}{c}\text { Promedio de } \\
\text { embriones } \\
\text { somáticos } \\
\text { por explante }\end{array}$ & $\begin{array}{c}\text { Embriones } \\
\text { maduros } \\
\text { germinados } \\
(\%)\end{array}$ & $\begin{array}{c}\text { Eficiencia de } \\
\text { regeneración } \\
\text { plantas/explante } \\
(\%)\end{array}$ \\
\hline ANA & 2 & $6.6 \pm 0.67 \mathrm{c}$ & $0.53 \pm 0.9 \mathrm{c}$ & $37.5 \pm 0.37 \mathrm{c}$ & $13.33 \pm 0.31 \mathrm{c}$ \\
& 5 & $26 \pm 0.8 \mathrm{~b}$ & $1.2 \pm 2.1 \mathrm{~b}$ & $77 \pm 0.2 \mathrm{a}$ & $26 \pm 0.37 \mathrm{~b}$ \\
$2,4-\mathrm{D}$ & 10 & $66.6 \pm 0.64 \mathrm{a}$ & $3 \pm 2.9 \mathrm{a}$ & $53.8 \pm 0.33 \mathrm{a}$ & $40 \pm 0.37 \mathrm{a}$ \\
& 5 & $20 \pm 0.81 \mathrm{~b}$ & $0.86 \pm 1.7 \mathrm{c}$ & $20 \pm 0.34 \mathrm{c}$ & - \\
Picloram & 10 & $6.6 \pm 0.67 \mathrm{c}$ & $0.13 \pm 0.22 \mathrm{~d}$ & $50 \pm 0.34 \mathrm{c}$ & - \\
& 0.05 & $20 \pm 0.81 \mathrm{~b}$ & $1.4 \pm 2.6 \mathrm{~b}$ & $71.4 \pm 0.24 \mathrm{~b}$ & $26 \pm 0.37 \mathrm{~b}$ \\
& 0.1 & $20 \pm 0.81 \mathrm{~b}$ & $1.46 \pm 2 \mathrm{~b}$ & $20 \pm 0.35 \mathrm{c}$ & $6 \pm 0.22 \mathrm{~d}$ \\
& 0.2 & $46.6 \pm 0.45 \mathrm{a}$ & $3.2 \pm 2.9 \mathrm{a}$ & $81.8 \pm 0.14 \mathrm{a}$ & $46 \pm 0.38 \mathrm{a}$ \\
\hline
\end{tabular}

El mayor número de plantas por explante se obtuvo con los tratamientos de $10 \mathrm{mg} \mathrm{L}^{-1}$ de ANA y $0.2 \mathrm{mg} \mathrm{L}^{-1}$ de picloram (46 y 40\%, respectivamente) (Cuadro 1). El sistema de regeneración por embriogénesis somática directa en aguacate no se había descrito anteriormente e implica una optimización del tiempo para obtener plantas completas. El proceso completo para obtener plantas desde la inducción de ES hasta la aclimatación en el presente trabajo llevó aproximadamente seis meses, mientras que en el reporte más reciente de regeneración de aguacate se requirieron hasta 14 meses (Encina et al., 2014).

\section{Embriogénesis indirecta}

Los EC de la accesión San Miguel cultivados en $0.2 \mathrm{mg} \mathrm{L}^{-1}$ de picloram desarrollaron callos embriogénicos (CE) (Figura 2A). El 50\% de los callos formados se mantuvieron en medio IC y el otro $50 \%$ fue transferido a medio M. De cada $50 \mathrm{mg}$ de CE en medio M (Figura 2B), se obtuvo el máximo potencial de regeneración entre el primer y tercer mes después de inducidos y no se encontraron diferencias significativas; en promedio 10.2 y 10 embriones maduraron (Figura 2C) y de estos germinaron 66 y $60 \%$ respectivamente (Figura 2D), de los cuales a su vez se obtuvieron 45 y 44\% de plantas completas (Cuadro 2). Al sexto mes el número de plantas disminuyó en 55\% mientras que en el noveno los embriones maduros perdieron su capacidad de germinar (Cuadro 2).

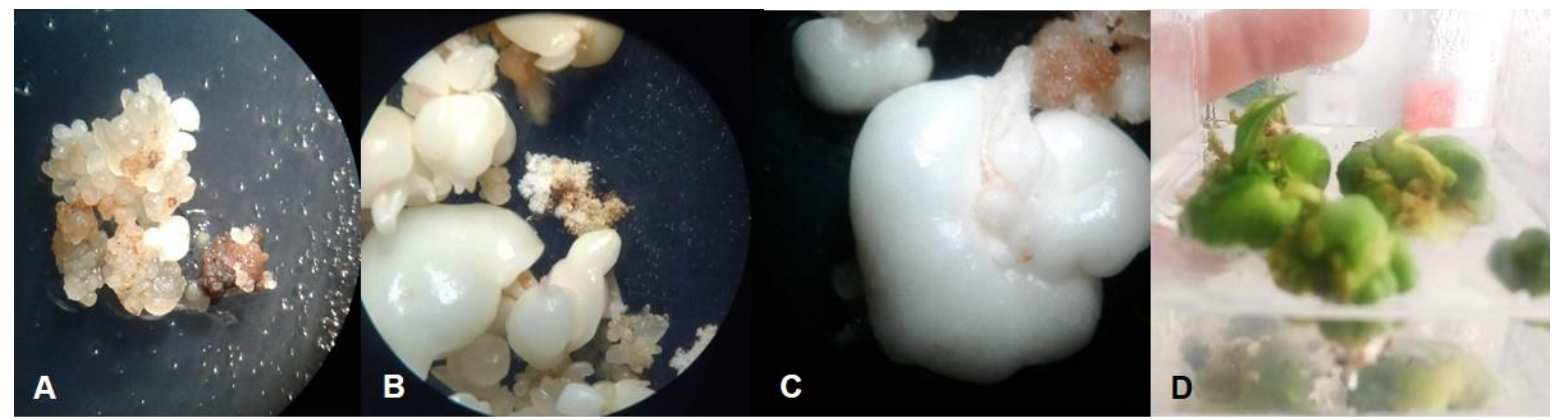

Figura 2. Embriogénesis somática indirecta en P. americana var. Drymifolia. A) callos embriogénicos; B) maduración de embriones somáticos (ES); C) ES maduro en medio de germinación; y D) plántulas en proceso de crecimiento. 
Cuadro 2. Regeneración de callos embriogénicos de $P$. americana var. Drymifolia accesión San Miguel.

\begin{tabular}{cccc}
\hline $\begin{array}{c}\text { Meses de subcultivo } \\
\text { después de la } \\
\text { inducción del callo }\end{array}$ & $\begin{array}{c}\text { Promedio de } \\
\text { embriones } \\
\text { maduros/50 mg de } \\
\text { callo }\end{array}$ & $\begin{array}{c}\text { Germinación de } \\
\text { embriones maduros } \\
(\%)\end{array}$ & $\begin{array}{c}\text { Eficiencia de regeneración } \\
\text { núm. plantas/núm. } \\
\text { embriones maduros (\%) }\end{array}$ \\
\hline Mes 1 & $10.2 \pm 2.6 \mathrm{a}$ & $66 \pm 2.31 \mathrm{a}$ & $45 \pm 2.1 \mathrm{a}$ \\
Mes 3 & $10 \pm 1 \mathrm{a}$ & $60 \pm 1.09 \mathrm{a}$ & $44 \pm 2.2 \mathrm{a}$ \\
Mes 6 & $4.0 \pm 1.41 \mathrm{~b}$ & $32 \pm 0.12 \mathrm{~b}$ & $25 \pm 0.44 \mathrm{~b}$ \\
Mes 9 & $2.2 \pm 2 \mathrm{c}$ & - & - \\
\hline
\end{tabular}

Witjaksono y Litz (1999) mencionan que el potencial embriogénico en condiciones de mantenimiento depende de la variedad y puede variar de tres meses a más de un año. Esta ruta de regeneración por embriogénesis indirecta se ha reportado para otras variedades de aguacate (Witjaksono y Litz, 1999; Encina et al., 2014) y en el presente estudio se muestra la primera evidencia para la variedad Drymifolia.

\section{Organogénesis}

La formación de brotes múltiples se indujo cuatro semanas después de que los EC decapitados (Figura 3A) permanecieran en el medio con reguladores de crecimiento (RC) (Figura 3B), mientras que los EC que se cultivaron en el medio sin reguladores de crecimiento (SRC) requirieron seis semanas para el desarrollo de brotes, aunque con menor eficiencia en todas las accesiones (Cuadro 3). Hasta ahora el uso de EC decapitados para inducir la organogénesis no se había descrito en el aguacate, pero si en otras especies (Quintero-Jiménez et al., 2010; Singh y Tiwari, 2012).

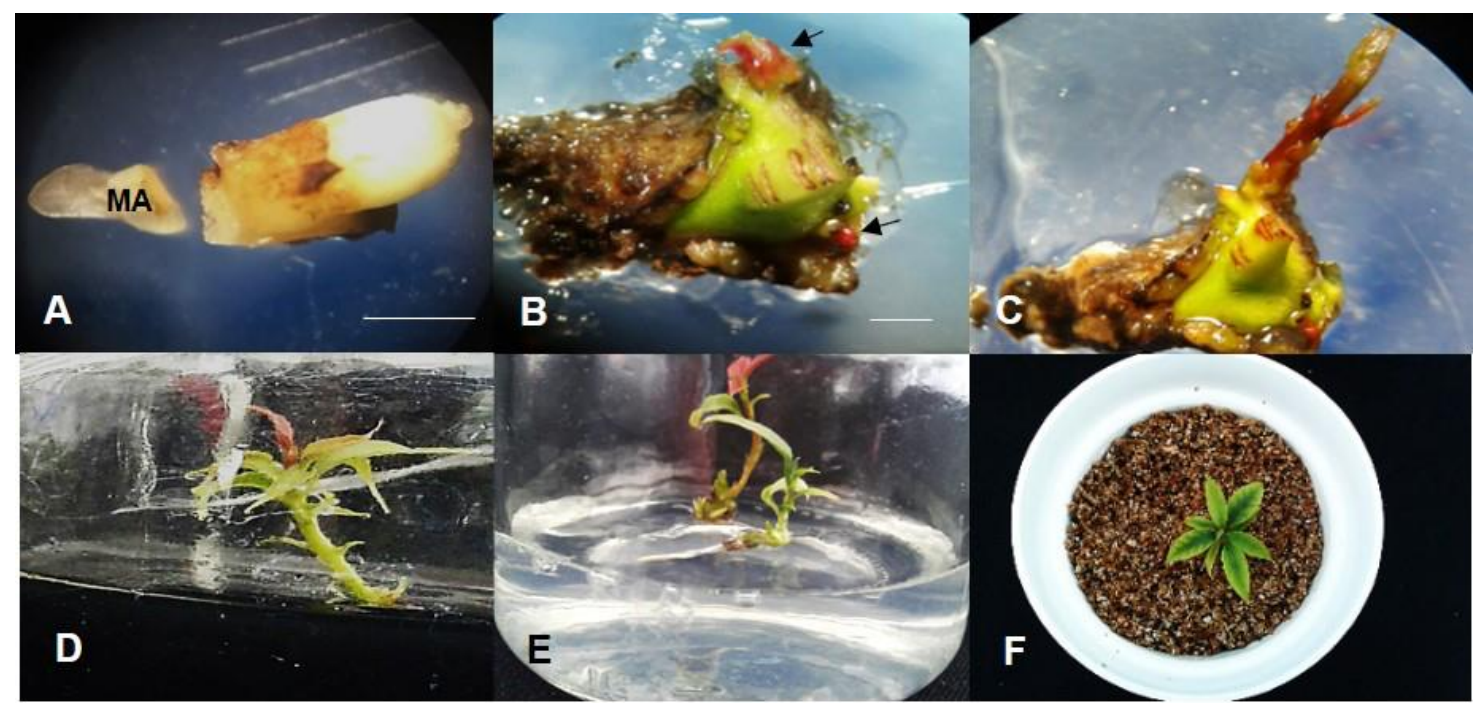

Figura 3. Regeneración de plantas de $P$. americana var. Drymifolia mediante organogénesis. A) embrión cigótico sin ápice meristemático (AM); B) brotes regenerados después de cuatro semanas en medio de inducción de organogénesis; C) brotes de dos meses en medio con reguladores de crecimiento; D) brotes en medio de enraizamiento; E) plántulas en medio de elongación después de tres meses de iniciado el cultivo; y F) planta aclimatada en condiciones de invernadero durante dos meses. 
En general, todas las accesiones de aguacate utilizadas en el presente estudio tuvieron respuesta organogénica (Cuadro 3). La accesión Comonfort 53 tuvo la mejor respuesta en el medio RC con respecto al número de explantes que formaron brotes (86\%), en tanto que las accesiones BG181 y BG24 mostraron los valores más bajos para esta variable cuando se cultivaron en un medio RC (14 y $26 \%$, respectivamente) (Cuadro 3).

Cuadro 3. Regeneración in vitro por organogénesis de diferentes accesiones de aguacate (Persea americana var. Drymifolia).

\begin{tabular}{cccccc}
\hline Accesión & $\begin{array}{c}\text { Reguladores } \\
\text { de } \\
\text { crecimiento }\end{array}$ & $\begin{array}{c}\text { Explantes con } \\
\text { brotes }(\%)\end{array}$ & $\begin{array}{c}\text { Promedio de } \\
\text { brotes por } \\
\text { explante }\end{array}$ & $\begin{array}{c}\text { Número total } \\
\text { de plantas }\end{array}$ & $\begin{array}{c}\text { Eficiencia de } \\
\text { regeneración } \\
\text { plantas/explante }(\%)\end{array}$ \\
\hline Celaya 79 & BAP+AG & $66 \pm 0.42 \mathrm{~b}$ & $1.93 \pm 1.23 \mathrm{~b}$ & $21 \pm 1.21 \mathrm{a}$ & $42 \pm 0.31 \mathrm{~b}$ \\
BG24 & SRC & $50 \pm 0.68 \mathrm{c}$ & $1.64 \pm 0.92 \mathrm{c}$ & $12 \pm 1.38 \mathrm{c}$ & $24 \pm 0.21 \mathrm{c}$ \\
& BAP+AG & $26 \pm 0.55 \mathrm{~d}$ & $1.15 \pm 1.12 \mathrm{~d}$ & $5 \pm 0.4 \mathrm{~d}$ & $10 \pm 0.11 \mathrm{~d}$ \\
BG181 & SRC & $10 \pm 0.51 \mathrm{e}$ & $1.4 \pm 2.6 \mathrm{c}$ & $1 \pm 0.13 \mathrm{~d}$ & $2 \pm 0.12 \mathrm{~d}$ \\
& BAP+AG & $14 \pm 0.59 \mathrm{e}$ & $1.14 \pm 1.72 \mathrm{~d}$ & $2 \pm 0.11 \mathrm{~d}$ & $4 \pm 0.23 \mathrm{~d}$ \\
& SRC & $12 \pm 0.5 \mathrm{e}$ & $1.16 \pm 1.23 \mathrm{~d}$ & $1 \pm 0.13 \mathrm{~d}$ & $2 \pm 0.12 \mathrm{~d}$ \\
Sutano & BAP+AG & $56 \pm 0.77 \mathrm{~b}$ & $2.35 \pm 1.91 \mathrm{~b}$ & $13 \pm 0.8 \mathrm{c}$ & $26 \pm 0.35 \mathrm{c}$ \\
& SRC & $30 \pm 0.43 \mathrm{~d}$ & $2.06 \pm 0.8 \mathrm{~b}$ & $4 \pm 0.31 \mathrm{~d}$ & $8 \pm 0.24 \mathrm{~d}$ \\
Comonfort 53 & BAP+AG & $62 \pm 0.76 \mathrm{~b}$ & $3.29 \pm 0.75 \mathrm{a}$ & $19 \pm 1.09 \mathrm{a}$ & $38 \pm 0.1 \mathrm{~b}$ \\
& BAPC & $40 \pm 0.46 \mathrm{c}$ & $3.05 \pm 0.95 \mathrm{a}$ & $11 \pm 0.52 \mathrm{c}$ & $22 \pm 0.14 \mathrm{c}$ \\
& SRC & $86 \pm 1.02 \mathrm{a}$ & $2.53 \pm 1.02 \mathrm{a}$ & $27 \pm 1.61 \mathrm{a}$ & $54 \pm 0.15 \mathrm{a}$ \\
\hline
\end{tabular}

$\mathrm{BAP}=6$-bencilaminopurina; $\mathrm{AG}=$ ácido giberélico; $\mathrm{SRC}=$ sin reguladores de crecimiento.

Las accesiones San Miguel y Comonfort 53 formaron el porcentaje más alto explantes con brotes, aunque no hubo diferencias significativas en el promedio de brotes por explante (3.29 y 2.53, respectivamente) (Cuadro 3). En contraste, Zulfiqar et al. (2009) observaron en aguacate del cv. Fuerte 2.5 brotes por explante con yemas axilares en comparación con 1.58 en las apicales. Por otro lado, en el presente trabajo se observó que Comonfort 53 y Celaya tuvieron un promedio de brotes por explante más bajo (2.53 y 1.93, respectivamente) comparados con San Miguel (3.29); sin embargo, el número de plantas por explante de Comonfort 53 y Celaya fue mayor (54 y $42 \%$ respectivamente) que San Miguel (38\%). Esto indica que la inducción inicial no siempre corresponde en la misma proporción a la diferenciación y el desarrollo de plantas completas (Cuadro 3).

Una vez que los brotes alcanzaron 2-3 cm de longitud después de dos meses de cultivo en el medio RC, se procedió a escindirlos del explante original (Figura 3C), antes de cultivarlos en el medio MR, en el que ocurrió la emergencia de la raíz después de 2 semanas (Figura 3D) y posteriormente transferidos a medio E (Figura 3E). Cuando las plántulas alcanzaron los $10 \mathrm{~cm}$ de largo se aclimataron (Figura 3F). Comonfort 53 tuvo la mayor eficiencia de regeneración (54\%), seguido de Celaya 79 (42\%) y San Miguel (38\%) (Cuadro 3). Esto es similar a lo descrito por MartínezPacheco et al. (2010) quienes mostraron una eficiencia de regeneración vía organogénesis de 
57.5\% para la variedad Drymifolia. Los resultados de este trabajo mostraron que el protocolo de regeneración in vitro para la variedad de aguacate Drymifolia mediante la vía de organogénesis con EC es funcional para las diferentes accesiones y el híbrido de Zutano.

\section{Conclusiones}

Se estableció un protocolo reproducible y eficiente para la regeneración in vitro de plantas de aguacate de la variedad Drymifolia utilizando seis accesiones. Este protocolo permitió regenerar plantas a partir de embriones cigóticos, por dos vías: embriogénesis somática y organogénesis. El uso de picloram $(0.82 \mu \mathrm{M})$ o ANA $(53.7 \mu \mathrm{M})$ induce la formación de embriones somáticos a través de la embriogénesis directa, mientras que el picloram $(0.82 \mu \mathrm{M})$ promueve la formación de callos embriogénicos por embriogénesis indirecta. Se estableció la propagación in vitro a través de la organogénesis utilizando embriones zigóticos decapitados. San Miguel fue la única con respuesta de embriogénesis somática, mientras que Comonfort 53 tuvo la mejor tasa organogénica. Por ambas vías de regeneración se obtuvieron plantas completas que se adaptaron a condiciones de invernadero en la mitad de tiempo que protocolos anteriores.

\section{Literatura citada}

Álvarez Acosta, C.; Marrero-Dominguez, A.; Gallo-Llobet, L. and González-Rodríguez, A. M. 2018. Physiological response of selected avocados (Persea americana) subjected to $\mathrm{NaCl}$ and $\mathrm{NaHCO}_{3}$ stress. Sci. Hortic. 237:81-88. Doi: 10.1016/j.scienta.2018.04.010.

Bonomelli, C.; Celis, V.; Lombardi, G. and Mártiz, J. 2018. Salt stress effects on avocado (Persea americana Mill.). Plants with and without seaweed extract (Ascophyllum nodosum) application. Agronomy. 8(5):64. Doi:10.3390/agronomy8050064.

Bandaralage, J. C. A. H., Hayward, A. and Mitter, N. 2017. Micropropagation of avocado (Persea americana Mill.). Am. J. Plant Sci. 8(11):2898-2921. Doi: 10.4236/ajps.2017.811197.

Encina, C. L.; Parisi, A.; O’Brien, C. and Mitter, N. 2014. Enhancing somatic embryogenesis in avocado (Persea americana Mill.) using a two-step culture system and including glutamine in the culture medium. Sci. Hortic. 165:44-50. Doi: 10.1016/j.scienta.2013.10.019.

FAOSTAT. 2018. Statistics of crops production by country. Food and Agriculture Organization, Rome. http://www.fao.org/faostat/en/\#data.

Fehér, A. 2019. Callus, dedifferentiation, totipotency, somatic embryogenesis: what these terms mean in the era of molecular plant biology? Front. Plant Sci. 10:536. Doi: 10.3389/fpls.2019.00536.

Fonseca-Duarte, P.; Alves-Chaves, M.; Dellinghausen-Borges, C. and Barboza-Mendonça, C. R. 2016. Avocado: characteristics, health benefits and uses. Cienc. Rural. 46(4):747-754. Doi: $10.1590 / 0103-8478 \mathrm{cr} 20141754176$.

Gamborg, O. L.; Miller, R. A. and Ojima, K. 1968. Nutrient requirements of suspension cultures of soybean root cells. Exp. Cell Res. 50(1):151-158. Doi: 10.1016/0014-4827(68)90403-5.

Gazit, S. and Degani, C. 2002. Reproductive biology. En: A.W. Whiley, B. Schaffer and B.N. Wolstenholme. (Eds.). The avocado botany, production and uses. CABI Publishing. New York, NY. 101-133 pp. Doi: 10.1079/9781845937010.0000.

Imbert, F. M. 1997. Delayed pistil senescence causes an overlap in protogyny in 'Tonnage' avocado. California Avocado Society Yearbook. 81:99-106. www.avocadosource.com/ CAS_Yearbooks/CAS_81_1997/CAS_1997_PG_099-106.pdf. 
Márquez-Martín, B.; Barceló-Muñoz, A.; Pliego-Alfaro, F. and Sánchez-Romero, C. 2012. Somatic embryogenesis and plant regeneration in avocado (Persea americana Mill.): influence of embryogenic culture type. J. Plant Biochem. Biotechnol. 21(2):180-188. Doi: 10.1007/s13562-011-0091-0.

Martínez-Pacheco, M. M.; Suárez-Rodríguez, L. M.; Hernández-García, A.; Salgado-Garciglia, R.; Fernández, I. V.; Palomares, M. E. A.; Cortés-Rodríguez, M. A. and López-Gómez, R. 2010. In vitro propagation of Mexican race avocado (Persea americana Mill. var. Drymifolia). Acta Hortic. 923(5):47-52. Doi: 10.17660/ActaHortic.2011.923.5.

Mooney, P. A. and Van Staden; J. 1987. Induction of embryogenesis in callus from immature embryos of Persea americana. Can. J. Bot. 65(4):622-626. Doi: 10.1139/b87-081.

Nhut, D. T.; Thi, N. N.; Khiet, B. L. T. and Luan, V. Q. 2008. Peptone stimulates in vitro shoot and root regeneration of avocado (Persea americana Mill.). Sci. Hortic. 115:124-128. Doi: 10.1016/j.scienta.2007.08.011.

Perán-Quesada R.; Sánchez-Romero, C.; Barceló-Muñoz, A. and Pliego-Alfaro, F. 2004. Factors affecting maturation of avocado somatic embryos. Sci. Hortic. 102:61-73. Doi: 10.1016/j.scienta.2003.12.003.

Pliego-Alfaro, F. and Murashige, T. 1988. Somatic embryogenesis in avocado (Persea americana Mill.) in vitro. Plant Cell Tiss. Org. Cult. 12(1):61-66. Doi: 10.1007/BF00043108.

Ploetz, R. C.; Schaffer, B.; Vargas, A. I.; Konkol, J. L.; Salvatierra, J. P. and Wideman, R. 2015. Impact of laurel wilt caused by Raffaelea lauricola, on leaf gas exchange and xylem sap flow in avocado, Persea americana. Phytopathol. 105(4):433-440. Doi: 10.1094/PHYTO07-14-0196-R.

Quintero-Jiménez, A.; Espinosa-Huerta, E.; Acosta-Gallegos, J. A.; Guzmán-Maldonado, H. S. and Mora-Avilés, M. A. 2010. Enhanced shoot organogenesis and regeneration in the common bean (Phaseolus vulgaris L.). Plant Cell Tiss. Org. Cult. 102(3):381-386. Doi: 10.1007/s11240-010-9744-2.

Raharjo, S. H. T. and Litz, R. E. 2003. Micrografting and ex vitro grafting for somatic embryo rescue and plant recovery in avocado (Persea americana). Plant Cell Tiss. Org. Cult. 82(1):1-9. Doi: 10.1007/s11240-004-5486-3.

Rincón-Hernández, C. A.; Sánchez Pérez, J. L. y Espinosa-García, F. J. 2011. Caracterización química foliar de los árboles de aguacate criollo (Persea americana var. Drymifolia) en los bancos de germoplasma de Michoacán, México. Rev. Mex. Biodiver. 82(2):395-412. https://www.redalyc.org/articulo.oa?id=42521043004.

SAS Institute Inc. 2012. Introduction to bayesian analysis procedures. In: SAS/STAT 9.2 User's Guide, Ch. 7. SAS Institute, Inc., Cary, NC. 141-179 pp.

Sharma, G.; Maymon, M. and Freeman, S. 2017. Epidemiology, pathology and identification of Colletotrichum including a novel species associated with avocado (Persea americana) anthracnose in Israel. Sci. Rep. 7:15839. Doi: 10.1038/s41598-017-15946-w.

Singh, J. and Tiwari, K. N. 2012. In vitro plant regeneration from decapitated embryonic axes of Clitoria ternatea L. an important medicinal plant. Ind. Crops Prod. 35(1):224-229. Doi: 10.1016/j.indcrop.2011.07.008.

Suarez, I.; Schnell, R.; Kuhn, D. and Litz, R. 2006. Recovery and indexing of avocado plants (Persea americana) from embryogenic nucellar cultures of an avocado sunblotch viroidinfected tree. Plant Cell Tiss. Org. Cult. 84(1):27-37. Doi: 10.1007/s11240-005-7532-1.

Van den Berg, N.; Christie, J. B.; Aveling, T. A. S. and Engelbrecht, J. 2018. Callose and B-1,3glucanase inhibit Phytophthora cinnamomi in a resistant avocado rootstock. Plant Pathol. 67(5):1150-1160. Doi: 10.1111/ppa.12819. 
Whiley, A. W.; Köhne, J. S.; Arpaia, M. L. and Bender, G. S. 1990. Future prospects with new avocado cultivars and elite rootstocks. South African Avocado Growers Association Yearbook. 13:16-20. http://www.avocadosource.com/Journals/SAAGA/SAAGA_ 1990/SAAGA_1990_PG_16-20.pdf.

Witjaksono; Litz, R. E. and Grosser, J. W. 1998. Isolation, culture and regeneration of avocado (Persea americana Mill.) protoplasts. Plant Cell Rep. 18(3-4):235-242. Doi: $10.1007 / \mathrm{s} 002990050563$.

Witjaksono and Litz, R. 1999. Induction and growth characteristics of embryogenic avocado cultures. Plant Cell Tiss. Org. Cult. 58(1):19-29. Doi: 10.1023/A:1006370912755.

Zulfiqar, B.; Abbasi, N. A.; Ahmad, T. and Hafiz, I. A. 2009. Effect of explant sources and different concentrations of plant growth regulators on in vitro shoot proliferation and rooting of avocado ( $P$. americana Mill.) Cv. 'Fuerte'. Pakistan J. Bot. 41(5):2333-2346. https://pdfs.semanticscholar.org/6857/306dc3a9af5f8ef7c2f0fd7e77868e05e3a3.pdf. 